\title{
Modular Web Portal Approach for Stimulating Home Renovation: Lessons from Local Authority Developments
}

\author{
Minyoung Kwon * and Erwin Mlecnik
}

check for updates

Citation: Kwon, M.; Mlecnik, E. Modular Web Portal Approach for Stimulating Home Renovation: Lessons from Local Authority Developments. Energies 2021, 14, 1270. https://doi.org/10.3390/ en14051270

Academic Editor: Ricardo Bessa

Received: 3 February 2021

Accepted: 21 February 2021

Published: 25 February 2021

Publisher's Note: MDPI stays neutral with regard to jurisdictional claims in published maps and institutional affiliations.

Copyright: (c) 2021 by the authors. Licensee MDPI, Basel, Switzerland. This article is an open access article distributed under the terms and conditions of the Creative Commons Attribution (CC BY) license (https:// creativecommons.org/licenses/by/ $4.0 /)$.
Department of Management in the Built Environment, Delft University of Technology, P.O. Box 5043, 2600 GA Delft, The Netherlands; E.Mlecnik@tudelft.nl

* Correspondence: M.Kwon@tudelft.nl

\begin{abstract}
Web portals have the potential to promote sustainable environmental ideas due to the capacity of digital media, such as easy accessibility, openness, and networking. Local authorities (LAs) are responsible for activating carbon savings in homes, and they are key actors when it comes to providing neutral information to their citizens. Local authority web portals may thus create environmental awareness, particularly regarding owner-occupied single-family home renovation. Nevertheless, the experiences of LAs developing web portals have rarely been studied. Therefore, this paper analyses the development process of various LA web modules and investigates how LAs foster modular web portals to stimulate the adoption of home renovation with parameters to assess LAs' actions in terms of the management of web-modules development. A homeowner renovation journey model is applied to map current local authority developments. Case study research and interviews were done to analyse and evaluate the adoption of modular web portals developed and tested by six local authorities in four countries in Europe. Based on the development and use of the modular web portal, lessons have been derived emphasising the importance of co-creation, integrating with offline activities, and a strategic management plan.
\end{abstract}

Keywords: home renovation; local authorities; homeowner-oriented approach; policy instrument; modular web portal; homeowner renovation journey

\section{Introduction}

Sustainable development needs implementation at a local level to achieve specific goals [1]. Decentralised actors such as local authorities (LAs) can be key actors for achieving energy policy goals [2], initiating leadership in innovation and regional actor networks [3], adaptation processes [4], and facilitating policies for household energy efficiency improvements [5]. The LAs, in this paper, include cities, municipalities, counties, and regional service departments. According to Dobers [6], LAs and private companies have collaborated in the field of environmental policy and management since the 1990s. Although LAs are well-positioned to support the adoption of low-carbon technologies, there are also limitations to their role. For example, the capacities of LAs are not well developed for LAs to reach out to the housing sector or specific types of homeowners. They also can have little involvement, limited experience, or capacity in energy provision [7].

The internet has become an important platform to promote sustainable environmental ideas and actions due to the capacity of digital media (for example: openness, easy accessibility, networking). In the government sector, the internet channel becomes an essential tool to provide service to citizens [8]. Some studies have identified how the digital and social media can amplify public perceptions towards a sustainable environment [9] and home renovation [10]. Melles, et al. [11] confirmed a relationship between digital media and home renovation. Digital and social media appeal to renovators for seeking advice and recommendations on home renovations through trusted parties. Early attempts to implement online forums on sustainable development were made by non-governmental 
organisations, aiming for modernising local government agenda [12]. Later, local governments developed websites and social media to disseminate sustainability policies and programmes to change awareness and to stimulate the engagement of citizens [13].

Homeowners tend to use various media across home renovation stages, from planning to adopting technologies, finding and validating reliable information, renovation measures, and products. Mediation in home renovation, however, raises an issue: reliability and trust. Homeowners are exposed to the enormous amount of information related to home renovation. However, it is difficult for homeowners to judge whether it is reliable information or not. According to Ebrahimigharehbaghi, et al. [14], homeowners tend to trust the information provided by non-profit organisations such as homeowner associations or governments. In addition, the information should be easily accessible, trustworthy, and specific, without being too generic [15]. In this regard, LAs are also often considered "trusted" actors. They can facilitate digital communication channels as a means of promoting energy-efficient and low-carbon home renovations. Their web portals have the potential to improve the effectiveness of sharing information and the adoption process of low-carbon technologies for homes. However, how can local authority web portals effectively be used to help homeowners in their renovation journey?

To activate its potential, the LAs do not only need an in-depth understanding of the practical process of launching web modules, they also need to identify collaboration strategies and communication plans. In this study, we applied a modular web portal design approach. The modular web portal breaks the contents on a web portal into modules. This creates flexibility, reusability, expandability, and independency of web components [16]. The main challenge is to identify a strategic approach to improve the quality of modular web portals in a way that a homeowner can collect reliable information and get familiar with the purpose, options, implementation, and experiences of low-carbon renovation solutions. This paper aims to contribute to such LA strategy development by providing a better understanding of how the development of web modules stimulating low-carbon home renovation can be improved.

\section{Methods}

\subsection{Research Goal}

This qualitative study explores the barriers and opportunities that LAs encounter in the practical development of web modules and digital information to support homeowner renovation journeys. It aims to develop recommendations for LAs to alleviate encountered barriers and to exploit opportunities, by testing a renovation journey research approach and model.

\subsection{Research Approach}

To answer the question "How can local authority web portals be more effective to help homeowners in their renovation journey?" a participatory research trajectory was started together with six LAs from four countries. The LA actors developing web portals included the city of Antwerp and EOS Ostend in Belgium, the public energy service of the region Hauts-de-France in France, the municipalities of Rotterdam and Breda in The Netherlands, and Kent County Council in the UK. During this four-year trajectory (January 2017-September 2020), each local authority provided information on preparing, scoping, developing, and evaluating new web modules for their web portals, as well as knowledge about the co-creation processes, the development of related business models, and the efforts for making web modules more self-sustaining.

The researchers participated in all related meetings as observers. The research thus comprised analysing various case studies (different web modules in different local authorities), as well as analysis of related documents, notes, minutes, and local-authority self-reporting. The researchers provided the above scoping and analysis model but did not interfere in local authority decision-making. 
In-depth interviews (see Table A2) were used to obtain additional detailed information and a better understanding of the web module development process. Six persons engaged in the strategic development of LA web modules from 2 regional (Kent County and Hauts-de-France), and 4 city-scale (Antwerp, Breda, Ostend, and Rotterdam) LAs were interviewed, and a content analysis [17] was applied. Based on specific evaluation parameters, interviews with LAs were conducted to collect information after having had the web modules online for at least 6 months, maximum 2 years.

\subsection{Evaluation of the Development Trajectory}

An evaluation of related LA actions aims to help LAs in speeding up the market uptake for retrofitting private homes. Although some studies have dealt with evaluating policy instruments, there are no clear policy evaluation criteria based on theories [18]. Instead, deductive research was used to identify key parameters that can lead to recommendations for other LAs. The development of web modules by LAs has not been widely discussed, and we therefore discuss literature mainly from other relevant areas such as e-government and web portal design. In the next section, we identify the key parameters to evaluate the LA modular web portal development.

\section{Evaluating Local Authority Web Portal Developments}

Bale, Foxon, Hannon and Gale [7] identified three main areas to assess potential roles and functions of strategic energy planning within local authorities. These areas can be assessed for our purpose to qualitatively understand how web modules can contribute to LA planning goals, and if they can be sustained. The three areas and specific issues in terms of web module development we consider here are:

- Strategic: this relates to developing the web modules (reflecting on the homeowner renovation journey) and its related co-creation.

- Technical: we focus on Information technology (IT) skills and legal issues such as privacy and security.

- Project (web portal) management: key parameters retained are quality control, maintenance, and communication.

These three areas and elements are further explained and discussed, and we unravel influencing factors, using additional literature sources.

\subsection{Developing Web Modules}

Homeowners are a key target group for LA communication to decrease energy consumption [15]. This means that it is vital to raise homeowners' awareness for energy savings. To achieve this in an effective manner, peer-to-peer communication is needed [19]: experienced homeowners are an important source of information for homeowners aspiring to renovate [20]. For stimulating market development, it is important to use confirmed positive experiences of homeowners to create awareness with new homeowners aspiring to renovate: "closing" the decision loop is important for upscaling market development.

\subsection{Co-Creation}

Supporting the homeowner renovation journey requires a bottom-up approach for delivering knowledge to homeowners. Co-creation is considered as an approach to solving problems through the open process of participation [21]. It is part of collaborative processes, and various stakeholders are involved. Internet intermediaries also play an important role in this modular web portal development because they serve internet-based services and access between third parties such as households, businesses, and government. The multiple actors take initiatives in a process. In public service, co-creation is defined as the involvement of citizens in the initiation and/or the design process of public services in order to (co)create beneficial outcomes' [22]. According to Voorberg, Bekkers and Tummers [22], the citizen plays a role as a co-implementer in many case studies. The purpose of cocreation is to gain more effectiveness, efficiency, and customer satisfaction. The definition 
of co-creation is sometimes broader than the involvement of citizens. Lelieveldt, et al. [23] present that co-creation is a joint responsibility of professionals and citizens. Co-creation concerns not only public participation but also a collaboration with other stakeholders.

\subsection{IT Skills}

The IT skills include system design, network construction, applications integration, system management, web development, and so on [24]. Launching and sustaining web modules requires well-trained IT staff. However, Moon [25] and Tung and Rieck [26] identified a lack of technical staff and technical expertise as a significant barrier to egovernment in practice. Municipal governments need support from the IT department or technically knowledgeable staff. We imagine (particularly smaller) LAs might have a shortage of technical expertise and IT training programmes and may encounter this barrier in the development of modular web portals and modules.

\subsection{Privacy and Security}

Privacy and security are some of the most crucial issues associated with internet-based communication and applications [27]. Digital information is often exposed to risks such as hacking and viruses. Citizens will be more active to approach the information when they feel it is trustworthy and safe [28]. McDonagh [29] and Carrizales, et al. [30] included privacy and security as evaluation criteria for local government websites. LAs need to organise security risk programmes, policy, and privacy laws since LA's web modules internally have databases which store citizens' profiles [31].

\subsection{Quality Control and Maintenance}

Citizens expect that information presented on a government web module or web portal is trustworthy and of high quality. Gilbert, et al. [32] highlighted the importance of information quality in municipal web portals. Almahamid, et al. [33] stated that higher information quality leads to higher intention to use the municipal portal for gathering information. The influencing factors for information quality were objectivity, accuracy, reliability, and usefulness [34,35]. In this regard, a modular structure can make a website easy to reuse, manage, and maintain by website managers [36].

\subsection{Communication}

Local authorities should get citizens' attention for adopting low-carbon retrofits by clarifying customer values for various target groups in their communication channels. The adoption of low-carbon technologies depends on how often homeowners are exposed to information they trust and that they can relate to their own financial budget, housing situation, technical concerns, and environmental and social values. Therefore, the LA has tasks to promote the benefits of low-carbon technologies and to propose solutions.

Interview questions were generated based on Table 1 showing the overview of the evaluation elements and objectives per each criteria.

Table 1. Perspectives, overview of evaluation elements, and expected results for assessing local authority web portal development.

\begin{tabular}{llll}
\hline Perspectives & Evaluation Elements & Expected Results \\
\hline Strategic & Developing web modules & $\bullet$ & Development process of web module contents \\
& Co-creation & $\bullet$ & Internal and external co-creation \\
\hline Technical & Information Technology (IT) skills & $\bullet$ & Capability to support modular web portal by local authorities (LAs) \\
& Privacy/security & $\bullet$ & Privacy and security management \\
\hline \multirow{2}{*}{ Management } & Quality control and maintenance & $\bullet$ & $\begin{array}{l}\text { Performance of web modules, quality of information, and sustaining } \\
\text { web modules }\end{array}$ \\
& Communication & $\bullet$ & Promoting home renovation technologies \\
\hline
\end{tabular}




\section{Results}

The paper analysed all available input related to the six evaluation elements listed in Table 1 and the scale of the LAs. The interview results gave further details as to how the LAs managed the web module development.

\subsection{Developing Web Modules}

The evaluation assesses the previously described closed-loop homeowner renovation journey. The LAs developed web modules based on the six homeowner renovation journey stages to support their communication strategies and enhance the adoption of low-carbon home renovation measures. We hypothesise with our model that a homeowner passes various stages before implementing low-carbon measures.

Table 2 shows the list of developed web modules by local authorities. The LAs created web modules which only partially covered one or more stages of a customer journey (see Figure 1). This was inherent to the development process: they could decide to focus on specific stages for which they felt their web portal was lacking development. Overall, LAs, regardless of their size, organised workshops (see Table A1) to decide the content of web modules with stakeholders. They reviewed already available information using the research model and thus found that modules relating to, for example, energy calculation, diagnosing homes, contracting, and funding, were largely missing in the existing web portals.

Table 2. Web modules implemented by seven local authorities.

\begin{tabular}{|c|c|c|}
\hline Journey Stages & Web Modules & Description \\
\hline Awareness & $\begin{array}{l}\text { Exemplars of retrofit in } \\
\text { your neighbourhood }\end{array}$ & $\begin{array}{l}\text { The web module shares the success stories of other homeowners. The module consists } \\
\text { of a map of the city where the story and information of successfully renovated houses } \\
\text { can be displayed. The visitor can type a zip code to access the related neighbourhood } \\
\text { and see possible example houses in that area. }\end{array}$ \\
\hline Awareness & $\begin{array}{l}\text { Thermographic map ( } 2 \text { modules } \\
\text { from different LAs) }\end{array}$ & $\begin{array}{l}\text { The web module presents thermal map of all roofs in a city. A homeowner can get the } \\
\text { thermal scan of his/her house by giving in his address. }\end{array}$ \\
\hline Awareness & Specialist advice & $\begin{array}{l}\text { A web module to inform inhabitants about the energy transition in general and the } \\
\text { possibilities of renovating their own home to a more } \mathrm{CO}_{2} \text { reduction home specifically. }\end{array}$ \\
\hline Attitude & One-stop-shop & $\begin{array}{l}\text { A web module in which customers/inhabitants can find support for the entire } \\
\text { customer journey. A 'one-stop-shop' [37] on the web portal as well as in real life. }\end{array}$ \\
\hline Attitude & $\begin{array}{l}\text { Information on and } \\
\text { registration to open-home events }\end{array}$ & $\begin{array}{l}\text { The web module provides information regarding open-home events or workshops. } \\
\text { People can register for the event in advance. }\end{array}$ \\
\hline Attitude & $\begin{array}{l}\text { Web-tool to calculate } \\
\text { energy and cost savings }\end{array}$ & $\begin{array}{l}\text { The web module provides calculations of energy and costs savings closer to reality. } \\
\text { That database is filled with pre-calculated values using a building simulation model. }\end{array}$ \\
\hline Access & Energy coach & $\begin{array}{l}\text { The web module connects to homeowners who visited a pop-up consultancy centre. } \\
\text { An energy coach schedules and gives advice by visiting registered people through this } \\
\text { web page. }\end{array}$ \\
\hline Access & Finance and funding & $\begin{array}{l}\text { The web page provides the various funding and finance mechanisms that residents } \\
\text { can benefit from to help them with their energy bills and to improve their } \\
\text { home environment. }\end{array}$ \\
\hline Access & How to find a craftsman & $\begin{array}{l}\text { Referral to a list of registered contractors, building partners, and websites offering } \\
\text { information/inspiration for renovation projects, as well as on workshops, } \\
\text { presentations, and/or ecological alternatives/solutions. The LA takes no liability for } \\
\text { the lists/websites that they link to, as they are owned and updated by third parties. }\end{array}$ \\
\hline Access & Referral forms & $\begin{array}{l}\text { The referral form allows residents to receive tailored information about funding and } \\
\text { quotes for insulation or new boilers. The referral form also allows residents to be } \\
\text { assessed for their eligibility for funding. }\end{array}$ \\
\hline Aid & $\begin{array}{l}\text { Handy tips when setting } \\
\text { up contracts }\end{array}$ & $\begin{array}{l}\text { The web module informs and provides tips for making a contract with } \\
\text { supply-side actors. }\end{array}$ \\
\hline Action & $\begin{array}{l}\text { Playlist of Do-It-Yourself films to } \\
\text { get inspired }\end{array}$ & $\begin{array}{l}\text { The web module shows how people can execute renovation measures in their house } \\
\text { by themselves. }\end{array}$ \\
\hline Acknowledgement & $\begin{array}{l}\text { Platform for homeowners } \\
\text { to exchange experiences }\end{array}$ & $\begin{array}{l}\text { The aim of the web module is to offer a platform to homeowners to share renovation } \\
\text { experiences with their neighbours. The web module consists of an interactive map } \\
\text { which shows the various renovations to their location on a map. }\end{array}$ \\
\hline
\end{tabular}




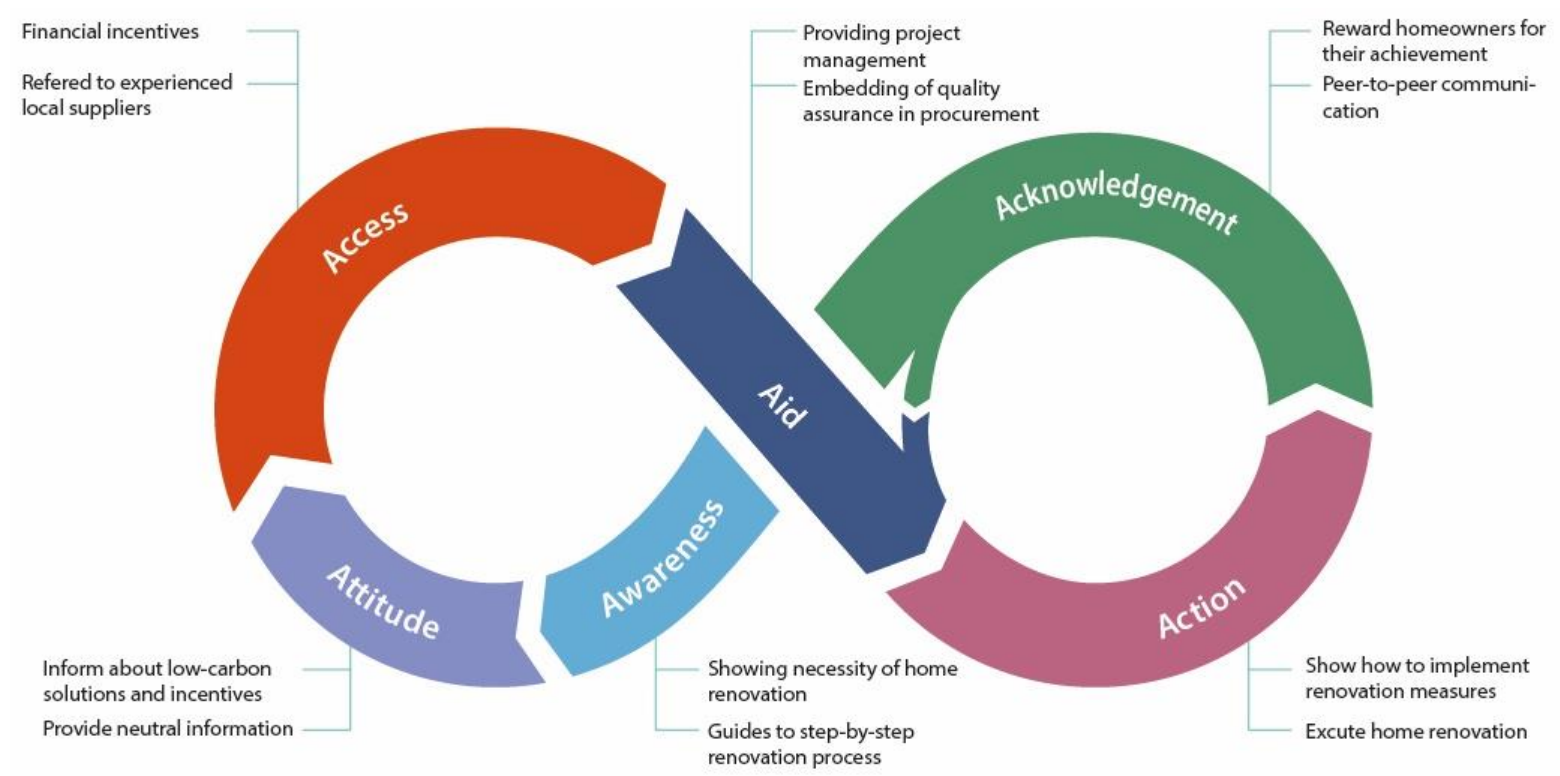

Figure 1. Homeowner renovation journey model to develop local authority web modules.

There are two patterns of how the LAs saw the contents of web-modules. Some LAs tried to develop add-on web modules which cover whole renovation journey stages. Some LAs created a new web portal for energy-efficient home and renovation, and the existing LA web portal provided the link to the new web portal. Others focused on providing additional textual content only, such as practical tips and information on financial incentives, information about events, or advice for low-carbon technology implementation. Following the launch of web developments, most LAs received additional requests, such as questions from homeowners about who they should work with. The LAs responded to such requests by integrating expected information into ongoing and developing web campaigns related to reducing carbon emissions and energy use. Most LAs fully integrated a selection of new web modules listed in Table 2 to the existing LA's web portal.

The interviewees reflected on perceived barriers and challenges of launching webmodules. This gave additional insights related to available financing, knowledge, and resources, and needed collaboration. This is illustrated with the following exemplary quotes.

IO: It was a challenge to reach people and collect their success stories because they do not want to share so much about them.

IR: We wanted to create an energy and $\mathrm{CO}_{2}$ calculation module because it is really practical and useful ... we could not manage it in the end because it needs experts who have sufficient knowledge about developing calculation tools.

IH: The LA renewed the entire web portal ... creating new content needed much more time than I expected. I recommend checking what information LAs already have instead of making new content. Maybe, they have enough information.

The development of some web modules-such as for sharing success stories in the neighbourhood-needed considerable development time, not only to find good content and examples but also to attract external content, for example, homeowners' contributions for statements. One medium-scale LA launched a thermographic map web module that shows whether a roof is well insulated and whether it is suitable for solar panels or a green roof. This was perceived as very effective to support the awareness-raising and attitude changing of homeowners, but also was a huge task for the LA, as it required specific project funding and experts. This LA had two external contractors: one to develop the map by flying over the city by airplane and another one to develop the website. 
Overall, LAs observed that web module developments require detailed planning of expertise, time, and cost. Usually, collaboration is organised through workshops and campaigns, and if needed, specific projects initiated and run by the LA. Interviewees recommended collaborating with other LAs, especially when the size of LA is not big enough to handle specific topics. LAs experienced that the development of some modules, such as the cost calculation tool, can be very complex and difficult to integrate in a regular renovation journey.

\subsection{Co-Creation}

The various LAs experimented with co-creative web module development. One LA invited homeowners for a workshop to get ideas for web module contents. However, homeowners were not systematically involved by every LAs. Other LAs focused more on exchanging knowledge with, for example, other LAs and policy actors or various internal LA departments.

On the one hand, small-scale LAs had to heavily rely on developing web modules and new content through co-creation. On the other hand, regional authorities aimed to convince LAs to support regional strategies as well. The LAs planned to invite other LAs for collaboration. This plan was easier for larger-scale LAs than for small-scale LAs. For one larger LA, the web module development resulted in a reinforced collaboration with a supply-demand intermediary actor and various internal departments to initiate a modular LA portal with a Customer relationship management (CRM) system. Co-creation with developers turned out to result in more or specific client-contractor relationships.

IB: Internal co-creation was a challenge due to the policy rule changes and other initial plans. Moreover, we could not handle everything ourselves, so we needed external support.

IK: We had co-creation with LAs from 12 districts and one unitary authority within our region.

In spite of the application of a step-by-step co-creation scheme, it turned out that co-creation processes were not always very successful. Internal co-creation was sometimes hindered by the fact that the vision for web development of the LA did not align with their own departmental and political goals. Small-scale LA collaborated with regional authorities, but this co-creation made the development more vulnerable and time-consuming. One regional-scale LA emphasised the need for internal co-creation and more support as a recent merger led to managing a larger region.

One regional-scale LA worked successfully together with small enterprises, a regional confederation of craftsmen, and a homeowners' association. Craftsmen were trained in lowcarbon solutions during co-creation. Especially, the homeowners' association contributed to promoting home renovation measures. The internal co-creation was also executed through workshops.

We, thus, detected several opportunities and barriers for LAs managing co-creation processes for web development: stakeholders are eager to collaborate, but there can also be long response times, no clear agreements on sharing of expertise, uncertainty about pricing, the responsibility of partners, and the future use of the co-created platform by other Las, and doubts about expertise. In co-creation processes, it is recommended to reflect on each partner's interest and to establish agreements in which phase of a home renovation journey this partner can be active.

\subsection{IT Skills}

One of the main challenges was that some LAs were not able to create web content themselves due to a lack of IT knowledge. For these reasons, most LAs had a contract with an external IT agency. The LA gives an assignment to the external company to build websites. Thus, it heavily relies on an IT agency, which might not be familiar with the specific information, module, or portal needs that were discussed in co-creation processes. Sometimes, bringing over this knowledge results in extra costs, which was 
not planned at the beginning. Small- and middle-scale LAs had an external contract with IT companies, while some middle- and regional-scale LAs could get support from their internal IT department. Nevertheless, similar communication barriers were perceived in both types of relations. One interviewee illustrated this:

IA: Our web portal has a very rigid structure, and it is not an interactive website. So, we need an external IT developer for technical changes.

Regional-scale LAs managed technical changes internally. Alternatively, IT developers were involved at the beginning, and later, the LA acquired sufficient IT knowledge to maintain the web modules, so they did not need an extra contractor for IT maintenance. LAs who had external contractors mentioned:

IB: The LA needs to be strict for deadlines and explain what the LA wants. Besides, the commitment of the contractor is essential.

IO: It is recommended to outline the structure of web modules well at the start to avoid unexpected cost. Of course, it is better to develop web modules internally if LAs can do it by themselves.

The interview results found that it is generally recommended to integrate new web modules to the existing web portal because of cost efficiency, less staff effort, and maintenance. However, when the existing web portal has a complicated structure, it can sometimes be better to create a new web platform with enhanced modularity. A drawback of existing LA web portals is that they can contain too many unstructured tabs and contents so that it may be difficult for visitors to find the information for which they are searching. The existing web portal can still link to (more topical) web modules for the ease of searching for information. Overall, it is still a big challenge for LAs to invest in a transition to modular web portals and e-services, using adapted IT contracts and collaboration.

\subsection{Privacy and Security}

During the development of the web modules, a European General Data Protection Regulation (GDPR, 2016) was locally implemented, leading to increased emphasis on privacy and security issues of developed web content and modules. All public information of the LAs had to follow GDPR. Privacy and security issues were also applied to specific modules, such as for collecting referral forms and for sharing experiences. Although people were offered to be able to withdraw their information any time they want, in general, they were more reluctant to share their experiences for being published on the web modules due to this increased media attention regarding privacy issues.

People who agreed with sharing their stories also requested minimum way of exposing their information. LAs asked to sign an agreement at the beginning or proposed options to participants regarding the extent to which they want to share their information, for example, full addresses, only street names, or district. One interviewee (IA) suggested protecting contributors' information as much as possible. This is already generally applied by their city for any information access. To avoid privacy issues, visitors can be asked to answer more neutral questions to get the right information. For example, questions can be about their roof (e.g., does it have solar panels? what kind of material it is made of?), and about their behaviour in winter (for example, do they turn on heating in the rooms located under the roof?). Asking these questions helps to provide highly related information to visitors while maintaining privacy. In addition, privacy-related information is not made public on web modules.

In another case, a LA was involved from the start of the renovation phase. The LA offered a contract stating that the homeowners agree with sharing information such as showing photos of their house, renovation measures, energy data, financial aid. The contract was part of the service offered by the LA to help the homeowners. However, when the LA asked them to participate in interviews or recording videos, only 15-20\% of homeowners who signed the contract joined further interviews. 


\subsection{Quality Control and Maintenance}

LAs updated web modules regularly by monitoring the use of web pages, collecting feedback from visitors, and by introducing new information. Information about financial incentives and types of subsidies had to be regularly updated based on new information provided by the central and local government. For the web module sharing success stories, energy experts first had to check the house and energy bill, so that the LA could decide whether the renovation was successful before disseminating the information from the homeowners. The LA explained that an evaluation session was helpful to improve the quality of web modules instead of only focusing on updating information. LAs recommended to not only assess the web modules internally but also to provide a space to collect feedback from visitors, either by e-mail or by other means, for example, a homeowner workshop.

During the interviews, we noted specific additional concerns. First, one LA never found time to internally discuss how they can improve quality control: the internal management was not performed ideally. Secondly, LAs were not allowed to recommend or provide specific contractors, suppliers, or construction companies because of required neutral procurement and consultancy. Instead of personal recommendations and referrals, some LAs provided a link to third-party, such as non-profit organisation, a regional confederation of contractors, and small and medium-sized enterprises (SMEs). By connecting to a third-party website, various LA websites could offer extensive and very concrete information on different themes as well as saving maintenance costs for LAs. Although LAs could not confirm the quality of, for example, listed renovation actors, this was the optimal way to keep themselves in a neutral position. One regional-scale LA launched web modules covering a whole region. Due to the required time and efforts, it was not easy to provide all information for an entire region. They suggested that maintaining the module by city-scale LAs can provide highly relevant and accurate information to citizens.

One interviewee stated a different point of view to look at quality control:

IP: Quality of contents is important, but the most important one is to make it easy for the homeowners to find the information. We experienced that people were struggling to find information because of many tabs and a complicated layout of the web portal.

This statement highlights that the functionality and easy readability and use of the website, and regular updates of web portal design, should also be considered.

\subsection{Communication}

LAs carried out online and offline advertisement to promote web modules. Smallscale LAs collaborated with third parties to do marketing and to build a communication strategy. LAs mainly promoted the web portal through online marketing such as social media, digital newsletter, and newspaper advertisement as a digital marketing strategy. They also held a communication campaign, roadshow, and a pop-up consultancy centre informing visitors about the web portal. However, this was organised for a specific period only. During the interview, practitioners from LAs suggested tips as below:

IO: face-to-face method was more efficient than advertising the home retrofits on newsletters or other digital methods.

IM: ... renovation coaches informed about the web modules ... I think it is an excellent opportunity to lead citizens to the web portal.

IA: Events through a consultancy centre are more successful and efficient than advertising through digital newsletters, social media, and flyers. However, it is costly because I staffed 4 to 5 people for one event.

LAs experimented with combining online and offline promotion. The statements of interviewees describe clearly that offline promotion was considered more effective than an online effort. This is because citizens could ask questions directly to advisors and consultants and LAs could establish the first contact for a trust relationship, by offering 
more precise information about what they are seeking. Nevertheless, all LAs also agreed that online and offline consultancy should be combined. The benefit of online efforts became evident when offline initiatives had to be cancelled due to the COVID-19 crisis.

\section{Discussion}

Development of modular web portals requires local authorities to spur them as instrumental policy means, while a methodological approach to evaluating such policy instruments is lacking [38]. The previous findings showed that research could help for evaluating a digital LA agenda. According to the policy-implementation gap defined by Gunn [39] highlighted in the recent study by Hudson, et al. [40], a full implementation plan or approach for LA actions has to be developed. Our research shows that, for developing essential elements of such a plan, it can be useful for LAs to think from the homeowner's perspective, particularly on needs for "trusted" digital information. The developed renovation journey model successfully allowed LAs to position web module development needs within their overall action plan.

\subsection{Strategic Management}

The contents of web modules were developed using a home renovation journey model for assessing needed actions. In practice, local authorities used this model for supporting a more bottom-up approach: the local digital status, stakeholder workshops, and engagement of different parties in the development process were key for identifying the needs within the journey. It may be difficult to involve other regional local authorities because of different political ambitions. Co-creation and collaboration are key, but the management of these processes in practice can be challenging, particularly for smaller local authorities.

\subsection{Technical Management}

In theory, having an internal IT department or IT-knowledgeable people in local authorities can boost not only the development of a modular web portal but also maintain it. Smaller LAs experience more difficulties with technical management. An existing external contract with an IT agency is not always adapted to web module development needs, and this can lead to unplanned costs to maintain, update, or redevelop a web portal. GDPR can be an important barrier for LAs to collect or share information in terms of privacy and security. LAs need to carefully take GDPR into account when developing digital strategies and actions.

\subsection{Project Management}

In practice, online and offline, LA developments are taking place simultaneously. They can reinforce each other but can also hinder each other if communication between both levels is not effective. LAs consider online modules as less effective compared to offline consultancy. However, offline consultancy requires a much higher budget. Communication of web modules supporting homeowner renovations has to be streamlined with overall LA sustainable housing communication. For larger authorities, this poses a challenge of harmonising communication efforts between various departments. Communication involving third-parties balances on the thread of public-private collaboration: due to strict procurement rules, LAs are often not keen on walking this line. In practice, the issue remains that homeowners will consult multiple websites to support their renovation journey. Visibility of developed LA web modules is key for their success.

\section{Conclusions}

\subsection{Recommendations for Local Authorities}

Some studies underlined that developing digital policy communication channels, such as web portals, based on innovation-decision processes, may help meet low-energy and low-carbon emission goals, particularly in the field of home renovation. This paper 
presented a theoretical framework, barriers, and practical recommendations for local authorities to speed up the adoption of renovation measures and to trigger homeowners to shift their energy perception. The theoretical analysis clarified six evaluation elements (developing web modules, co-creation, IT skills, privacy and security, quality control and maintenance, and communication) for modular web portal development into: strategic, technical, and project management. The six elements can help practitioners to develop, implement, and sustain web modules for stimulating home renovation, but can also be used in a more general context for assessing web module developments. This study revealed opportunities, barriers, and ideas to eliminate barriers that should be considered, exemplifying the development of modular web modules by local authorities, to accelerate home renovations.

- Internal and external co-creation can relieve financial and technical burdens of LAs' modular web portal development (for example, involving other LAs, associations, and so on). Particularly, co-creation is essential for small-scale LAs: they can invite neighbouring LAs to develop web modules together.

- Using a "home renovation journey" as a theoretical framework, LAs can reflect if their web development provides advice and information in different stages of a home renovation process.

- LAs are often considered a trusted source of information, which can also be exploited digitally. LAs can further work together with other reliable and trusted sources, for example citizens, as peer-to-peer communicators, non-profit organisations, energy agencies, construction associations, public-private-civic intermediaries, and so on.

- Integrating web modules into an existing LA web portal is recommended for long-term financial effectiveness and will be easier if the web portal is already modular.

- Regarding privacy and security, LAs need to carefully balance the scale for sharing information: homeowners and others have to agree with sharing at the beginning of the consultation process.

- Collaborating with third parties can improve the quality of information, and the ease of maintenance.

A specific development trajectory of web modules-reflecting on the homeowner renovation journey—can give the local authorities additional insights, particularly about what type of 'trusted' information is still needed by local homeowners. Identifying these needs and the consequent web module development can benefit from collaboration and co-creation with other policy actors and citizens, private actors, and public-private-civic intermediaries.

\subsection{Limitations}

The interview-based research focused on the LAs' perspectives in terms of developing a modular web portal. Further study, therefore, has to include visitors and quantitative research to demonstrate the effectiveness and efficiency of launched web modules on shifting homeowners' awareness and adoption of home renovation measures.

Author Contributions: Conceptualisation, M.K.; methodology, M.K.; validation, M.K. and E.M.; formal analysis, M.K.; original draft preparation, M.K.; writing-review and editing, M.K. and E.M.; visualisation, M.K.; supervision, E.M.; project administration, E.M.; funding acquisition, E.M. All authors have read and agreed to the published version of the manuscript.

Funding: This research was funded by the European Fund for Regional Development and the Provinces of South Holland and West Flanders under the project Interreg 2 Seas "Triple-A: stimulating the Adoption of low-carbon technologies by home-owners through Awareness and easy Access", grant number 2S02-029, and the APC was funded by Delft University of Technology.

Institutional Review Board Statement: Not applicable.

Informed Consent Statement: Not applicable.

Data Availability Statement: The data presented in this study are available on request from the corresponding author. The data are not publicly available due to the privacy of interviewees. 
Acknowledgments: The authors would like to thank all Triple-A contributors and partners from six local authorities, particularly Oubbol Oung (City of Rotterdam) for coordinating implementations of LA web portal developments. This work is developed also in collaboration with the IEA EBC Annex 75 Cost-effective Building Renovation at District Level Combining Energy Efficiency \& Renewables.

Conflicts of Interest: The authors declare no conflict of interest.

\section{Appendix A}

Table A1. List of workshops.

\begin{tabular}{cc}
\hline Aim of Workshop & Date \\
\hline Scoping workshop & 18 May 2017 \\
Feasible co-creation scheme & 12 December 2018 \\
Implementation and exploitation plan & 10 September 2019 \\
Local stakeholder workshop & 8 November 2019 \\
\hline
\end{tabular}

Table A2. List of interview-guide questions.

General questions

Co-creation

Strategic

Developing web modules

IT skills

Technical

Privacy/security

Quality control

Management
- What problems or obstacles were you confronted with during the development of the modules? How did you deal with that?

- $\quad$ Based on your experiences with the development of your web modules, what tips can you give to other LA's/regions that also like to develop your web module?

- Have you conducted any external or internal co-creation?

- Do you have a strategic plan for co-creation? Which partners, and in which way?

- Barriers? Tips and recommendations?

- What aspect of the homeowner renovation journey did you focus on?

- Barriers? Tips and recommendations?

- How did you integrate the web modules? Is it a totally new web portal, or integrated into the existing LA web portal?

- Was it difficult to apply web module?

- Tips and recommendations?

- How did you handle privacy and security issues?

- Barriers? Tips and recommendations?

- How did you do quality control of web modules?

- How did you decide the information is trustworthy?

- $\quad$ Are there any difficulties?

- Tips? Recommendations?

- How did you maintain the web modules?

- Are there any difficulties?

- Tips? Recommendations?

- How did you do marketing to activate the web modules and increase the success of the web portal or web modules? (e.g., more visitors)?

Marketing
Examples can be using social media, sending letters, and so on.

- $\quad$ Are there any difficulties?

- Tips? Recommendations? 


\section{References}

1. Graute, U. Local authorities acting globally for sustainable development. Reg. Stud. 2016, 50, 1931-1942. [CrossRef]

2. Allman, L.; Fleming, P.; Wallace, A. The progress of English and Welsh local authorities in addressing climate change. Local Environ. 2004, 9, 271-283. [CrossRef]

3. von Malmborg, F. Conditions for regional public-private partnerships for sustainable development-Swedish perspectives. Eur. Environ. 2003, 13, 133-149. [CrossRef]

4. Laudien, R.; Boon, E.; Goosen, H.; van Nieuwaal, K. The Dutch adaptation web portal: Seven lessons learnt from a co-production point of view. Clim. Chang. 2019, 153, 509-521. [CrossRef]

5. Tambach, M.; Hasselaar, E.; Itard, L. Assessment of current Dutch energy transition policy instruments for the existing housing stock. Energy Policy 2010, 38, 981-996. [CrossRef]

6. Dobers, P. Organising Strategies of Environmental Control: Towards a Decentralisation of the Swedish Environmental Control Repertoire; Wiley: Stockholm, Sweden, 1999.

7. Bale, C.S.; Foxon, T.J.; Hannon, M.J.; Gale, W.F. Strategic energy planning within local authorities in the UK: A study of the city of Leeds. Energy Policy 2012, 48, 242-251. [CrossRef]

8. Soliman, K.S.; Affisco, J.F.; Shackleton, P.; Fisher, J.; Dawson, L. E-government services in the local government context: An Australian case study. Bus. Process Manag. J. 2006, 12, 88-100.

9. Podkalicka, A.M.; Milne, E.; Hulse, K.; Winfree, T.; Melles, G. Hashtag Sustainability? Home Renovators' Media World; CRC for Low Carbon Living: Sydney, Australia, 2016.

10. Hunter, S. Media-Engaged Home Renovation and the Transition to Zero Carbon Homes; RMIT University: Melbourne, Australia, 2019.

11. Melles, G.; Hulse, K.; Podkalicka, A.; Milne, E.; Winfree, T. Designing in'-Media and Communications for Low Carbon Home Renovation; CRC for Low Carbon Living: Sydney, Australia, 2017.

12. Dyer, L. Engaging Environmental Practitioners in Online Forums to Discuss Sustainability Issues: A useful process? Local Environ 2002, 7, 311-316. [CrossRef]

13. Podkalicka, A.; Winfree, T.; Wright, A.; McGregor, J. Sharing Advice Online to Foster Sustainable Homes. In Decarbonising the Built Environment; Palgrave Macmillan, Springer: Singapore, 2019; pp. 469-488.

14. Ebrahimigharehbaghi, S.; Qian, Q.K.; Meijer, F.M.; Visscher, H.J. Unravelling Dutch homeowners' behaviour towards energy efficiency renovations: What drives and hinders their decision-making? Energy Policy 2019, 129, 546-561. [CrossRef]

15. Risholt, B.; Berker, T. Success for energy efficient renovation of dwellings_-Learning from private homeowners. Energy Policy 2013, 61, 1022-1030. [CrossRef]

16. Curtis, N. Modular Web Design: Creating Reusable Components for User Experience Design and Documentation; Pearson Education: London, UK, 2010.

17. Erlingsson, C.; Brysiewicz, P. A hands-on guide to doing content analysis. Afr. J. Emerg. Med. 2017, 7, 93-99. [CrossRef]

18. Shahab, S.; Clinch, J.P.; O'Neill, E. Impact-based planning evaluation: Advancing normative criteria for policy analysis. Environ. Plan. B Urban Anal. City Sci. 2019, 46, 534-550. [CrossRef]

19. Rogers, E.M. Diffusion of Innovations; Simon and Schuster: New York, NY, USA, 2010.

20. Wilson, C.; Crane, L.; Chryssochoidis, G. Why do homeowners renovate energy efficiently? Contrasting perspectives and implications for policy. Energy Res. Soc. Sci. 2015, 7, 12-22. [CrossRef]

21. Maase, S.; Dorst, K. Co-creation: A way to reach sustainable social innovation. In Perspectives on Radical Changes to Sustainable Consumption and Production; Wiley: Copenhagen, Denmark, 2006.

22. Voorberg, W.H.; Bekkers, V.J.; Tummers, L.G. A systematic review of co-creation and co-production: Embarking on the social innovation journey. Public Manag. Rev. 2015, 17, 1333-1357. [CrossRef]

23. Lelieveldt, H.; Dekker, K.; Völker, B.; Torenvlied, R. Civic organizations as political actors: Mapping and predicting the involvement of civic organizations in neighborhood problem-solving and coproduction. Urban Aff. Rev. 2009, 45, 3-24. [CrossRef]

24. Ebrahim, Z.; Irani, Z. E-government adoption: Architecture and barriers. Bus. Process Manag. J. 2005, 11, 589-611. [CrossRef]

25. Moon, M.J. The evolution of e-government among municipalities: Rhetoric or reality? Public Adm. Rev. 2002, 62, 424-433. [CrossRef]

26. Tung, L.L.; Rieck, O. Adoption of electronic government services among business organizations in Singapore. J. Strateg. Inf. Syst. 2005, 14, 417-440. [CrossRef]

27. Soliman, K.S.; Affisco, J.F.; Belanger, F.; Hiller, J.S. A framework for e-government: Privacy implications. Bus. Process Manag. J. 2006, 12, 48-60.

28. Georgescu, M. Egovernment: New perspectives on the futhre of government digitisation. Ann. Univ. Apulensis-Ser. Oeconomica 2012, 14, 369-384.

29. McDonagh, M. E-government in Australia: The challenge to privacy of personal information. Int'l JL Info. Tech. 2002, 10, 327. [CrossRef]

30. Carrizales, T.; Holzer, M.; Manoharan, A. Worldwide E-Governance: A Longitudinal Assessment of Municipal Websites and the Digital Divide. In E-Government Research: Policy and Management; IGI Global: Hershey, PA, USA, 2008; pp. 98-119.

31. Lambrinoudakis, C.; Gritzalis, S.; Dridi, F.; Pernul, G. Security requirements for e-government services: A methodological approach for developing a common PKI-based security policy. Comput. Commun. 2003, 26, 1873-1883. [CrossRef] 
32. Gilbert, D.; Balestrini, P.; Littleboy, D. Barriers and benefits in the adoption of e-government. Int. J. Public Sect. Manag. 2004, 17, 286-301. [CrossRef]

33. Almahamid, S.; Mcadams, A.C.; Al Kalaldeh, T.; MO'TAZ, A.-S.E. The relationship between perceived usefulness, perceived ease of use, perceived information quality, and intention to use e-government. J. Theor. Appl. Inf. Technol. 2010, 11, 30-44.

34. Magal, S.R. A model for evaluating information center success. J. Manag. Inf. Syst. 1991, 8, 91-106. [CrossRef]

35. Prybutok, V.R.; Zhang, X.; Ryan, S.D. Evaluating leadership, IT quality, and net benefits in an e-government environment. Inf. Manag. 2008, 45, 143-152. [CrossRef]

36. Dervos, D.A.; Psarras, K. A framework for the design of an extensible modular academic web site. In Proceedings of the 2nd International Scientific Conference on Information Technology and Quality, Spetses, Greece, 4-5 June 2005; pp. 12-19.

37. Nations, U. United Nations E-Government Survey 2014: E-Government for the Future We Want; United Nations: New York, NY, USA, 2014.

38. Weber, M.; Driessen, P.P.; Runhaar, H.A. Evaluating environmental policy instruments mixes; a methodology illustrated by noise policy in the Netherlands. J. Environ. Plan. Manag. 2014, 57, 1381-1397. [CrossRef]

39. Gunn, L.A. Why is implementation so difficult? Manag. Serv. Gov. O M Bull. Lond. 1978, 33, 169-176.

40. Hudson, B.; Hunter, D.; Peckham, S. Policy failure and the policy-implementation gap: Can policy support programs help? Policy Des. Pract. 2019, 2, 1-14. [CrossRef] 